\title{
Early faults diagnosis and severity assessment of rolling element bearings on wireless signal transfer
}

\author{
Ghulam Mustafa ${ }^{1}$, Shahab Khushnood ${ }^{2}$ \\ ${ }^{1}$ Department of Mechanical Engineering, University of Engineering and Technology, Taxila, Pakistan \\ ${ }^{2}$ Department of Mechanical Engineering, WAH Engineering College, WAH, Pakistan
}

\begin{tabular}{l} 
Article Info \\
\hline Article history: \\
Received Aug 30, 2021 \\
Revised Nov 23, 2021 \\
Accepted Jan 6, 2022 \\
\hline Keywords: \\
Fault diagnosis \\
Machine fault diagnosis \\
condition monitoring \\
Roller bearings \\
Vibration analysis \\
autocorrelation \\
Wireless sensor network
\end{tabular}

Wireless sensor network

\begin{abstract}
Machine condition monitoring in remote locations and harsh environment where network infrastructure is not feasible, or hardwired network connectivity is not possible, wireless communications provides an alternative which also offer installation cost savings, improve reliability and quicker deployment. This paper describes the implementation of wireless sensor network (WSN) for early fault diagnosis of rolling element bearings based on signal autocorrelation technique. A low-power $2.4 \mathrm{GHz}$ wireless HART transceiver, a low-cost wireless vibration transmitter, $26.76 \mathrm{mv} / \mathrm{g}$ accelerometers and a 1420 wireless gateway with AMS software was implemented. The research describes the methodology of acquiring peak values data in high frequency region. The noise was averaged out by applying four-time averaging and natural frequencies or fault frequencies of bearing elements was captured. The experimental results show that the signal autocorrelation algorithm can successfully diagnose the roller bearing faults at early stage on wireless signal transfer. As the raw data was processed before wireless transmission on analyzing unit and spectrum was transferred in JPG format on display unit, minimum power consumption has been noted. The technique provided a better alternative of wired system for real time condition monitoring of roller bearings in rotating equipment installed in remote area.
\end{abstract}

This is an open access article under the CC BY-SA license.

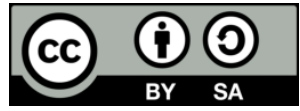

\section{Corresponding Author:}

Ghulam Mustafa

Department of Mechanical Engineering, University of Engineering and Technology

QR8G+PCM, Taxila, Rawalpindi, Punjab, Pakistan

Email: ghulam.mustafa@students.uettaxila.edu.pk

\section{INTRODUCTION}

On-line data collection remains a number of barriers like high cost of installation, especially in hazardous areas. Permanent installation for moving equipment in harsh environment is not justified due to extra expenses included fiber optic cable, conduit installation, trenching and installation of festooning. Studies show that the average price for cable installation is $\$ 40$ per foot in process industries. For on-line vibration monitoring a high-quality cable is also required for continuous and high-speed data intensive. The wireless technology overcome these barriers. The wireless ethernet in industrial environments use radio frequency (RF) transmission with $2.4 \mathrm{GHz}$ and $5.8 \mathrm{GHz}$ bands. The wireless condition monitoring (WCM) offer lower installation costs. The wireless network has been used for structure health monitoring on for condition assessment of bridge, turbine blade and aircraft structure [1]-[6].

Bao et al. [1] worked on vibration signals analysis of a bridge structure based a group sparse optimization algorithm with compressive sensing technique on wireless sensors network. Carbajo et al. [2] recognized the wireless platform by using three wireless sensor systems for vibration monitoring of turbine blade with sine sweep. Saxena and Tandon [3] discusses the structural health monitoring of machines by 
comparing wireless technology with already existing wired system. Sergievskiy and Syroezhkin [4] used strain gauges on WSN for stress measurement of aircraft structure. Vujić et al. [5] describes the application of WSNs for aircraft structural health monitoring by using micro electro mechanical systems (MEMS) for tracking the load history of helicopter. Contreras and Ziavras [6] proposed a frequency domain pattern matching technique based on vibration analysis to perform modeling of structure on a wireless signal network by using a damaged beam. Khan and Zanwar [7] measured the temperature, pressure and ultrasonic data of oil to monitor the chemical and physical properties on wireless system by using Zigbee protocol. Michala and Lazakis [8] presented the work for pressure measurement of an air pump with wireless data transmission on a Zigbee module. Olalere and Dewa [9] presented a remote condition monitoring approach for surveillance of elevators on wireless network. The condition monitoring of rotating equipment with vibration analysis on wireless network provides the availability of equipment for long term operation. Elnady et al. [10] performed the modal analysis of shaft with variation of speed from using impulse-response method on the wireless sensor network (WSN). Murthy et al. [11] worked on a motor-pump set for classical faults analysis i.e., rotor unbalance, misalignment and wear and tear of components. The induction motor condition and faults has been studied by using wireless network [12]-[15]. V et al. [12] worked on condition monitoring of induction motor using vibration, temperature, speed, humidity, supply voltage and motor current analysis. Rane and Khedkar [13] compared wireless and wired system for condition monitoring of induction motor. Medina-García et al. [14] presented work on vibration, motor current and temperature analysis for detection of mechanical faults with wireless network.

Korkua et al. [15] studied vibration under different levels of imbalance conditions and investigated behavior of a 3-phase induction machine on WSN. Machine condition monitoring of rotating equipment are subjected to surveillance of bearing's health. In rolling element bearings, Hertz contact stresses occur on the balls and the raceways due to the pressure between the metal's surfaces. Due to bearing damage, high frequency vibration (over $20 \mathrm{kHz}$ in the earliest stag) but low in amplitude is generated. These high frequency pulses cannot be recorded with conventional root mean square (RMS) technique. Therefore, we need techniques which can remove the low frequency, high amplitude vibration in order to detect high frequency, low amplitude source of vibration. Signal enveloping and demodulation has been used for capturing the short duration spikes for bearing health monitoring. The wired system has been used for bearing fault analysis with number of signal processing techniques [16]-[19]. Vinaya et al. [16] proposed the non-negative matrix factorization (NMF) method for fault diagnostics of damaged bearing in rotary screw compressor. Xu et al. [17] used the envelope analysis technique with harmonic-to-noise ratio to capture the periodic impulses on a bearing test rig. Ren et al. [18] used envelope order spectrum analysis with Wavelet and Hilbert transform. Yassine et al. [19] used the envelope analysis for observations of various bearing fault condition.

The wireless system has been successfully applied for roller bearings faults analysis with demodulation and envelope analysis technique [20]-[27]. Feng et al. [20] used envelope analysis on a wireless sensor for bearing fault analysis with reduce data size and power consumption technique. Ikram et al. [21] presented the work for identification of ball-bearing problems of a motor on a wireless vibration system by using vibration enveloping technique and temperature measurement. Sadiki et al. [22] worked on real-time monitoring for predictive analysis of a Turbine's thrust bearing using wireless signal transverse technique. Myhrea et al. [23] presented work on vibration monitoring with wireless sensors on motor-pump set in a water pumping station. Ramirez et al. [24] presented the work on on wireless vibration monitoring using power spectral distribution (PSD) and enveloped signal analysis technique. In [25], [26] proposed optimum band-pass filtering with envelope analysis on a WSN for bearing fault diagnosis. Lu et al. [27] investigated bearings condition using the under sampled signals acquired on a WSN.

Like enveloping and demodulation, signal autocorrelation technique can also be used to detect the bearings faults by monitoring vibration at a very high rate. With autocorrelation technique, high-frequency stress waves can be detected to monitor the roller bearing health. In this paper we used the WSN for early fault diagnosis of roller bearings by using signal autocorrelation technique. To minimize the transfer load of vibration data, the frequency spectrum has been transferred in JPG file using wireless HART protocols. The research also describes the requirements of wireless instrumentation, sampling setting to capture the frequency peaks in high frequency region. The behavior of under stress faulty bearing and a good bearing bearing on WSN has been experienced. A test rig has been devised and a low-power $2.4 \mathrm{GHz}$ wireless HART transceiver, a low-cost wireless vibration transmitter, $26.76 \mathrm{mv} / \mathrm{g}$ accelerometers and a wireless gateway with AMS software has been implemented.

\section{THEORETICAL BACKGROUND}

The short duration higher frequency waves called stress waves are generated when a rolling element in a bearing passes over a defect. The parameters required to captured these stress waves are amplitude, time 
and rate at which stresses are occurring. We required to calculate the amplitude $(\mathrm{x})$, time (t) and frequency (f) at which these stress events are occurring. The autocorrelation signal processing technique can be used to calculate these parameters. With autocorrelation, we captured, and analyzed the sequential discrete time intervals for identifying bearing defects frequencies i.e., BPFO, BPFI, BSF and FTF. These impacts are measured in G's in the peak values of time waveform. This analysis enables for identification as well as severity assessment of the defects in roller bearings. The highest amplitude signal (peak value) due to stress waves are holds then signal in G's is passed through a high pass filter greater than or equal to the Nyquist frequency. This high frequency impacting data (peak) acquired after removing the machine noise and unwanted low frequencies which are due to imbalance, misalignment, looseness or resonance etc. For analysis the data is then brought back to fundamental frequency with in F-Max as shown in Figure 1.

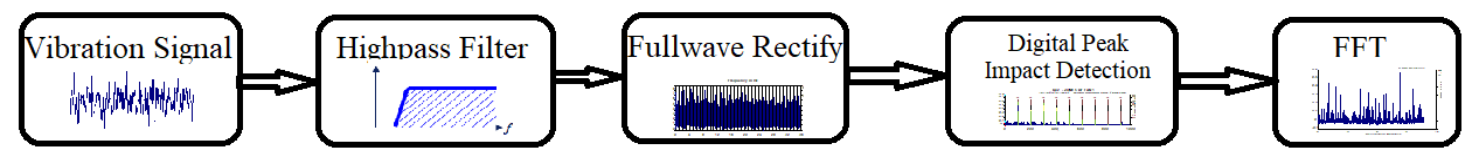

Figure 1. The data processing for signal autocorrelation technique

The auto correlation function is a strong tool for analyzing periodic vibration signals (repeating pattern) in time domain. The autocorrelation signal processing technique not only enhance the signal but also remove the noise from the signal. The autocorrelation function of $\mathrm{x}(\mathrm{t})$ is given as:

$$
R_{x}(\tau)=\lim _{T \rightarrow \infty}\left(\frac{1}{T}\right) \int_{0}^{T} X(t) x(t+\tau) d t
$$

Where $R_{x}(\tau)$ is autocorrelation function, $\mathrm{X}(\mathrm{t})$ is signal at time " $\mathrm{t}$ " and " $\mathrm{T}$ " is total time. This continuous function is converted from continuous (analog) to discrete with A/D converter and low pass filter eliminate any aliasing. The envelope of a bearing vibration signal usually consists of the periodic fault signal and background noise, which can be described as:

$$
Y(t)=x(t)+w(t)
$$

Where $\mathrm{x}(\mathrm{t})$ is fault impact generated periodically and $\mathrm{w}(\mathrm{t})$ is white noise or unwanted signals. So, the autocorrelated function may be given as:

$$
R_{y y}(\tau)=R_{x x}(\tau)+R x w(\tau)+R w x(\tau)+R w w(\tau)
$$

Being random signal, white noise become zero and we can omit it. So we conclude from (3) as:

$$
R_{y y}(\tau)=R_{x x}(\tau)
$$

If number of points are 1024, then a set of numbers for 400-line resolution may be represented as a set by: $\{\mathrm{Xi}\}=\mathrm{X} 1, \mathrm{X} 2, \mathrm{X} 3, \ldots \mathrm{X} 1024$.

If " $\tau$ " is the lag time and by integrating $x(t) x(t+\tau)$ the autocorrelation function becomes:

$$
R=\frac{1}{M} \sum_{i=1}^{M} X_{i} X_{i+j}
$$

where $M$ is equal to or less than $N / 2$ number of points for $\left\{X_{i}\right\}$ both in positive and negative. If $j=1$ (mean square), then (5) become mean square of $\left\{\mathrm{X}_{\mathrm{i}}\right\}$. If $\{\mathrm{Ri}\}$ is set of autocorrelation function then first component in the autocorrelation set $\{\mathrm{Ri}\}$ is the largest and noise tends to disappear, a new function $(\mathrm{Cj})$ become:

$$
C j=\frac{1}{R 1}[R 1, R 2 \ldots . R M]
$$

The $\mathrm{Cj}$ values are between \pm 1 . The noise will be average out to zero. So " $\mathrm{Cj}$ " is a measure of the degree of correlation at each value of $j(t)$ with highly correlated values approaching \pm 1 . It means we isolates the peak energy of interest. 


\section{SYSTEM IMPLIMENTATION AND DATA ACQUISITION}

An experimental test rig was devised which consists on a motor running at $1465 \mathrm{rpm}(24.41 \mathrm{~Hz})$, flexible coupling, two roller bearings and a disk of aluminum weighing 270 gm rotating between the bearings. The data was collected on test rig bearings housing as shown in Figure 2. Wireless vibration sensors (piezoelectric accelerometers) of $26.76 \mathrm{mv} / \mathrm{g}$ with integrated cable attached with wireless transmitter 9420 were installed on the bearing (UC204-12) casings of test rig in radial and and axial directions.

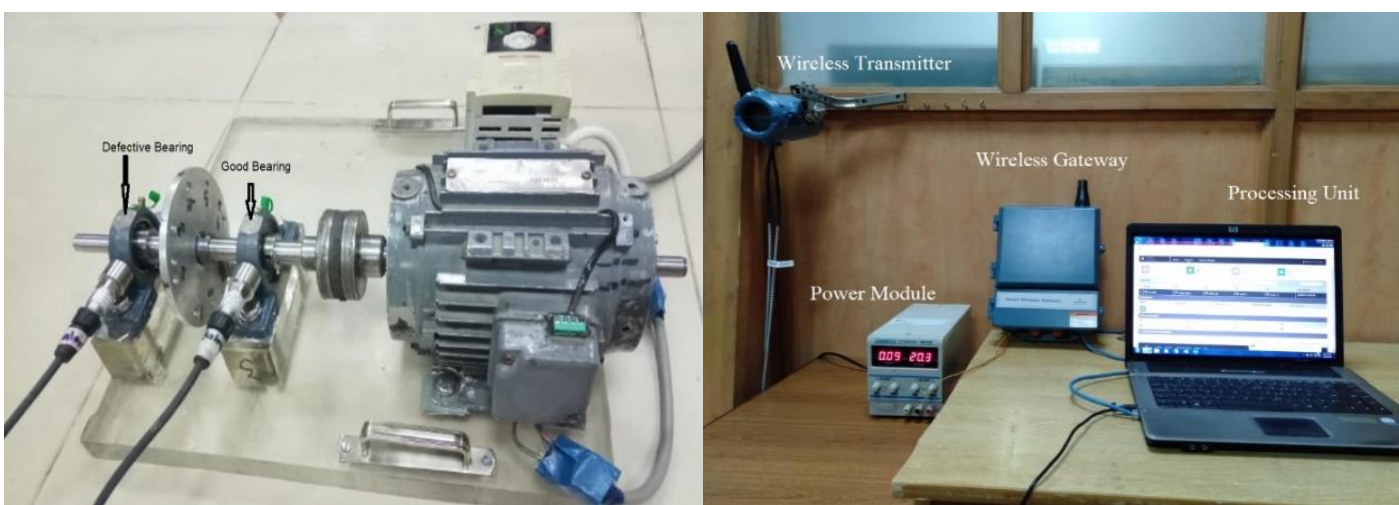

Figure 2. The experimental test rig with wireless signal transfer set-up

The bearing installed between coupling and aluminum disk is a good bearing with no physical damage while the second bearing installed at outside of test rig is same type defective bearing with miner damaged cage. The induced defect of the roller bearing is shown in Figure 3. The geometric parameters of UC 204-12 roller bearing were calculated with following formulas [25]:

$$
\begin{aligned}
& \text { (Ball Spin Frequency) } B S F=\frac{D}{2 d}\left[1-(d / D)^{2} \operatorname{COS}^{2}(\varnothing)\right. \\
& \text { (Fundamental Train Frequency) } F T F=\frac{f r}{2}\left[1-\left(d /{ }_{D}\right) \operatorname{COS}(\varnothing)\right] \\
& \text { (Ball pass Frequency Outer race) } B P F O=\frac{n f r}{2}\left[1-\left(d /{ }_{D}\right) \operatorname{COS}(\varnothing)\right] \\
& \text { (Ball pass Frequency Inner race) } B P F I=\frac{n f r}{2}[1+(d / D) \operatorname{COS}(\varnothing)]
\end{aligned}
$$

Where " $\mathrm{d}$ " is the roller diameter, " $\mathrm{D}$ "is the pitch diameter, $f \mathrm{r}$ is the shaft speed, " $\mathrm{n}$ "is the number of rolling elements and " $\varnothing$ "is the bearing contact angle. The frequency factors of UC 204-12 roller bearing are given in Table 1.

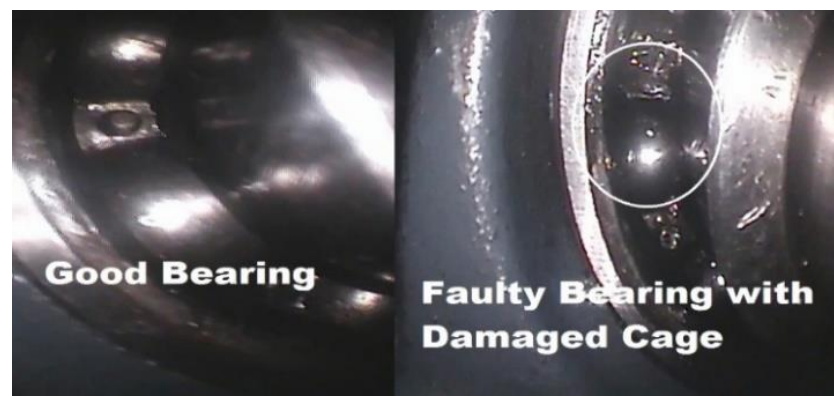

Figure 3. The good and defective bearing used for analysis for wireless CM

The test rig was powerup and data was collected in horizontal, vertical and axial direction on healthy and defective bearings. The vibration data acquisition and signal transmission is in a sequence that the accelerometers captured vibration signal then transmitted the signal to wireless Hart transmitter 9420 at $60 \mathrm{sec}$ 
transmission rate and transmission speed around $250 \mathrm{kbps}$. Sensors communicate with gateway 1420 through vibration transmitter wirelessly as data packets transverse. At the receiving end, gateway receives the data and create the timewave form and frequency spectrum in graphical representation. On PC (display unit), the data is received via ethernet cable. The block diagram of wireless condition monitoring system (hardware and software), requirements and communication are shown in Figure 4. A $1000 \mathrm{~Hz}$ high pass filter with four-time averages has been set.

Table 1. Bearing characteristic frequencies $(\mathrm{Hz})$ for $1465 \mathrm{rpm}$

\begin{tabular}{lcc}
\hline \multicolumn{1}{c}{ Frequency factor (FF) } & Basic Fr. factors & Frequency (Hz) \\
\hline Over rolling FF on outer ring & 3.0522 & 74.50 \\
Over rolling FF on inner ring & 4.9478 & 120.77 \\
Over rolling FF on rolling element & 1.9916 & 48.61 \\
Ring pass FF on rolling element & 0.3815 & 9.312 \\
\hline
\end{tabular}

The rule of thumb is to set the FMAX greater than $3^{\text {rd }}$ hormonic of frequency relevant to component having maximum frequency. The maximum fault frequency of roller bearing UC 204-12 is the ball pass frequency of the inner race (BPFI) of i.e., 120.77, so we have set the frequency span $1000 \mathrm{~Hz}$ (F-Max) which is more than 3rd hormonic of BPFI i.e. $362.31 \mathrm{~Hz}$. The acquired data captured the peak values in high frequency region and unwanted peaks were removed. The data was brought back to below $1 \mathrm{KHz}$ for visualization and early fault diagnostics of bearings. The noise was averaged out and natural frequencies or fault frequencies of bearing elements were captured successfully.
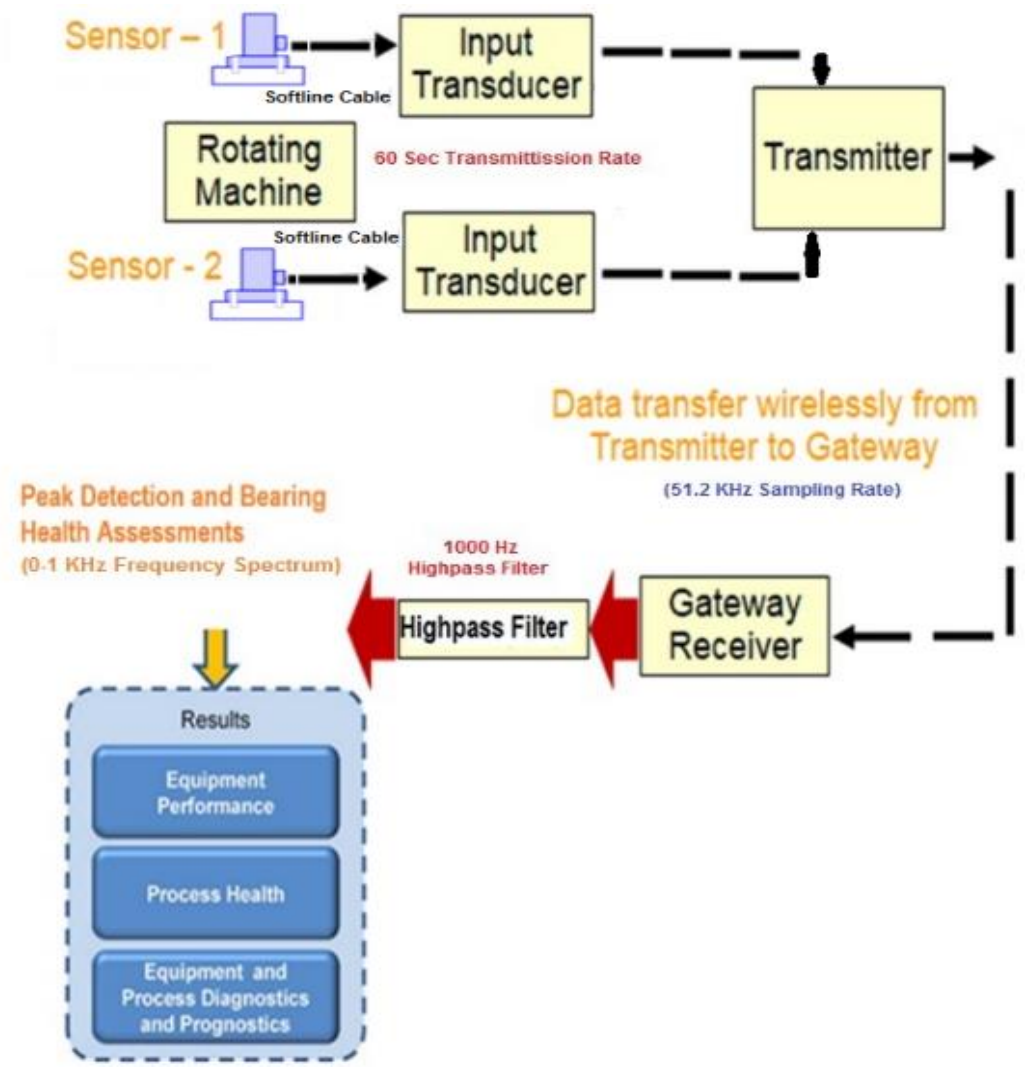

Figure 4. Flow chart of router configuration from transmitter to gateway and coordination unit

\section{RESULTS AND DISCUSSION}

The high frequency spikes due to excitation of natural frequency of bearing elements were captured using auto correlation technique on wireless network. The captured frequency spectrums in form of G's transferred in JPG format through wireless-hart protocol are shown Figures 5-7. The RMS values of good bearing in horizontal direction is $1.069 \mathrm{~g}$ as shown in Figure 5(a) whereas defective bearing exhibit $2.198 \mathrm{~g}$ as 
shown in Figure 5(b). Similarly, in Figures 6(a) and (b), the RMS value of good bearing is $1.728 \mathrm{~g}$ and defective bearing has extended value of RMS i.e $2.774 \mathrm{~g}$. The RMS expression of good and defective bearing in axial direction also confirm the condition of good and defective bearingare as shown in Figures 7(a) and (b). It is noted that good bearing has almost half value i.e. $0.528 \mathrm{~g}$ than the defective one which has $1.216 \mathrm{~g}$ RMS.

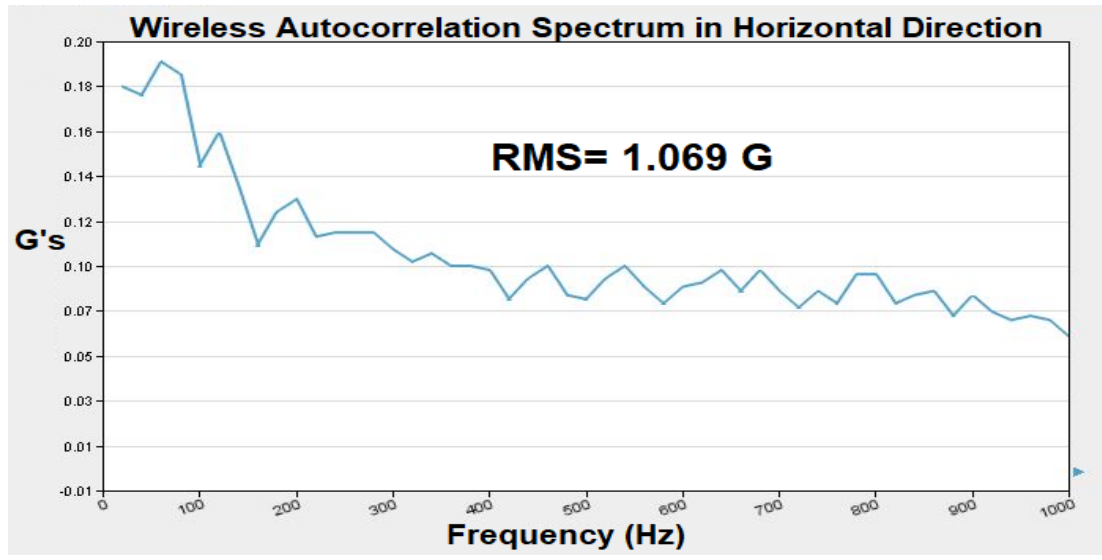

(a)

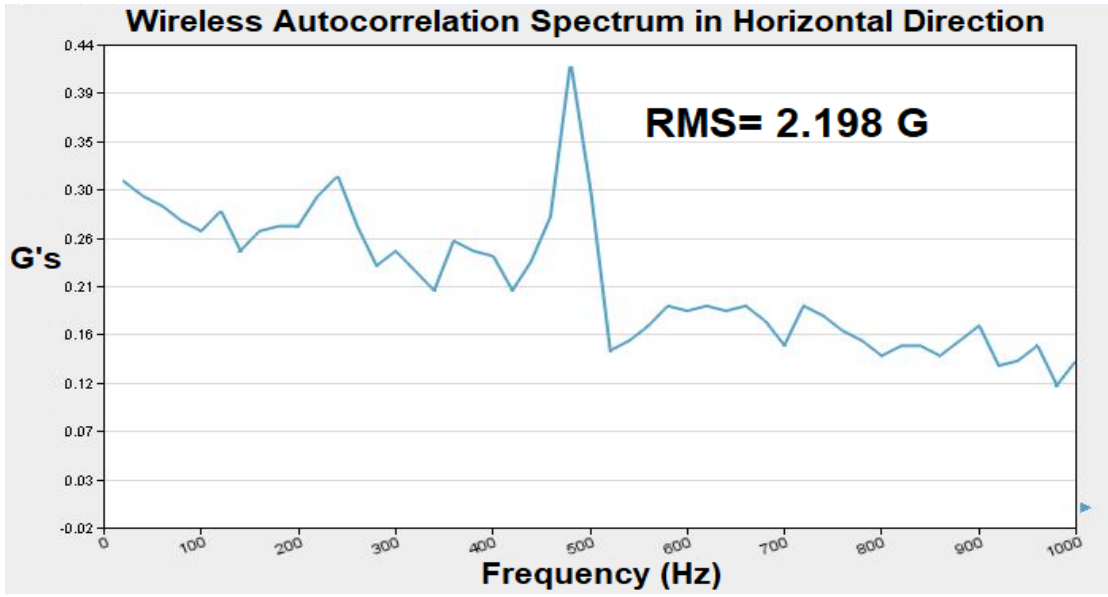

(b)

Figure 5. Wireless autocorrelation frequency spectrum acquired in horizontal direction (a) good bearing and (b) defective bearing

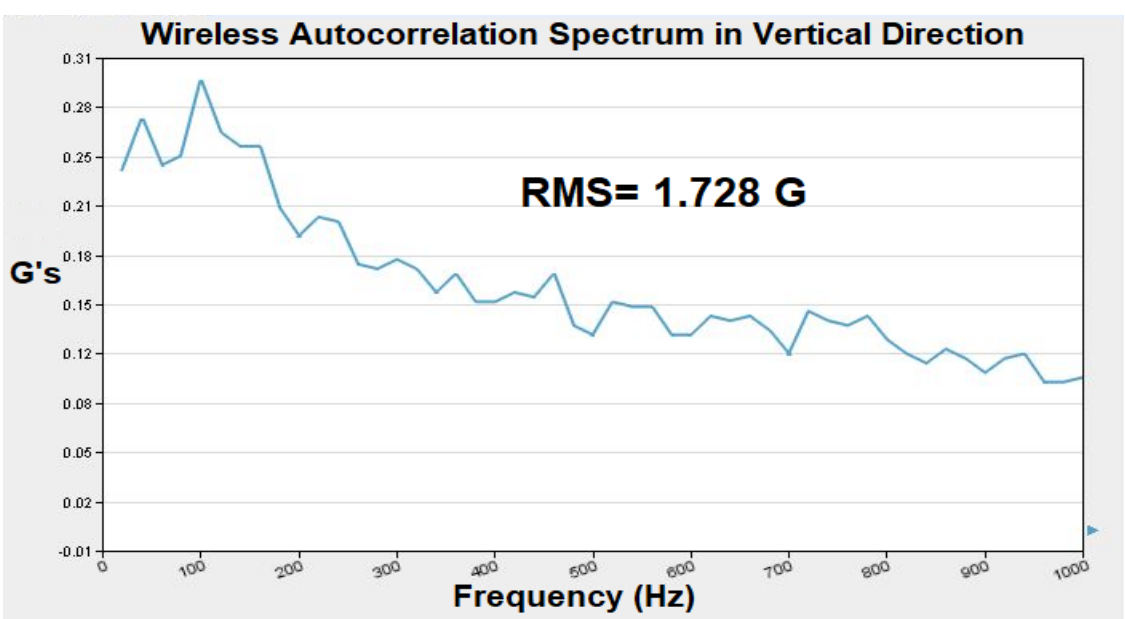

(a)

Figure 6. Wireless autocorrelation frequency spectrum acquired in vertical direction (a) good bearing 


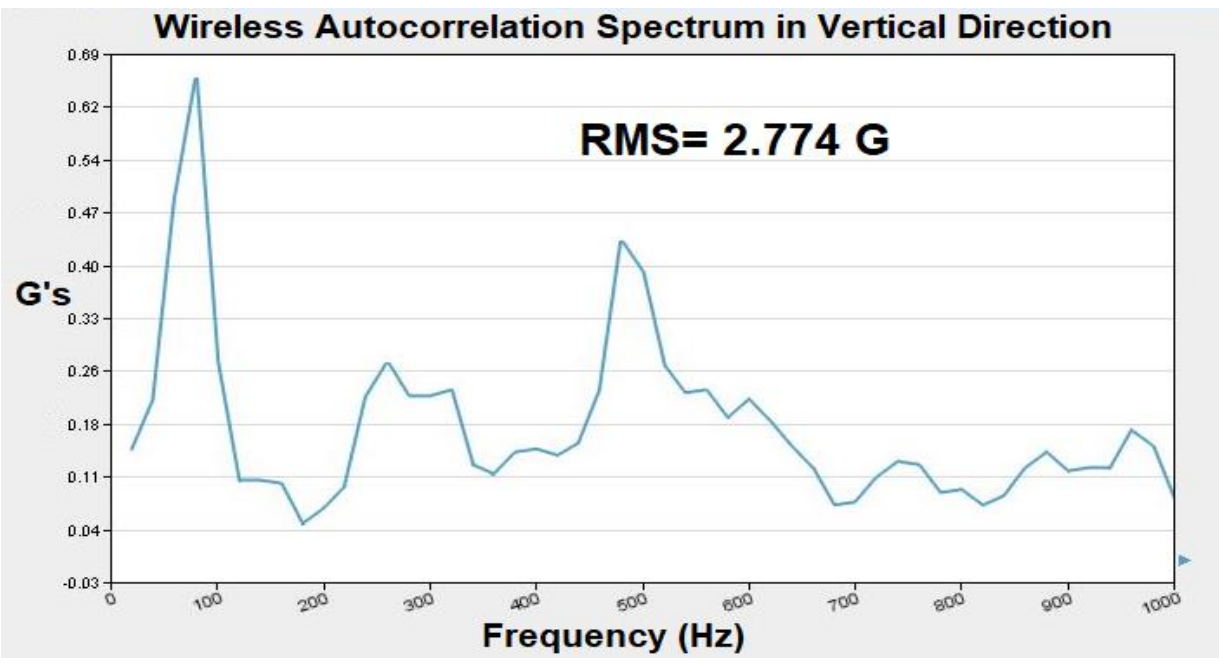

(b)

Figure 6. Wireless autocorrelation frequency spectrum acquired in vertical direction (b) defective bearing (continue)

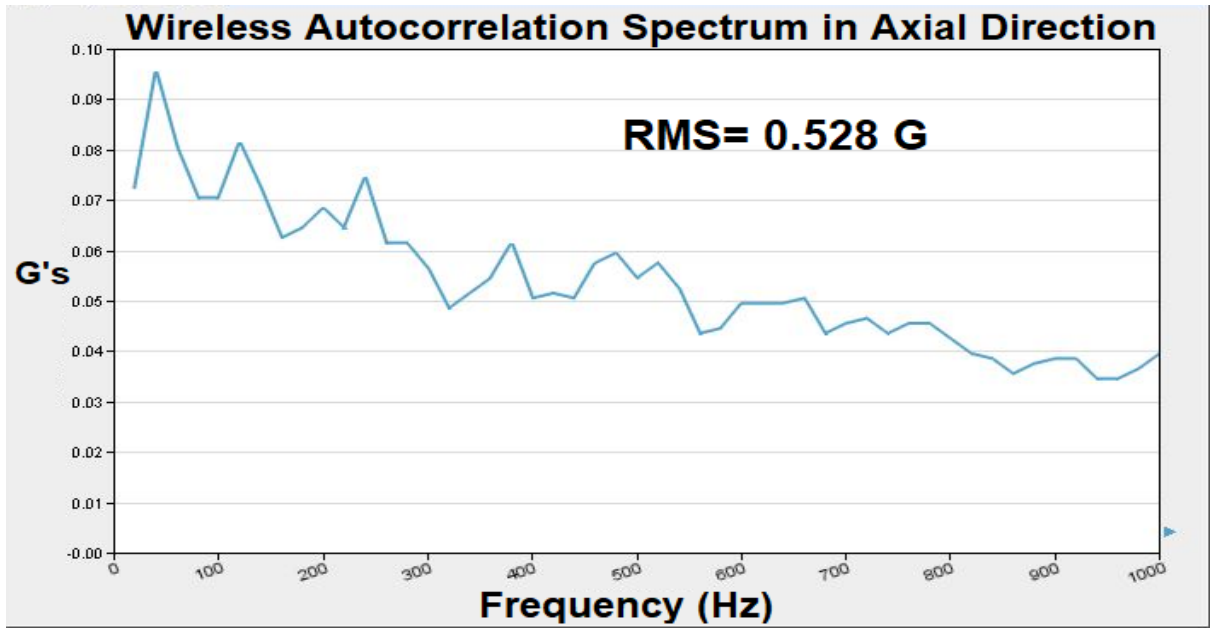

(a)

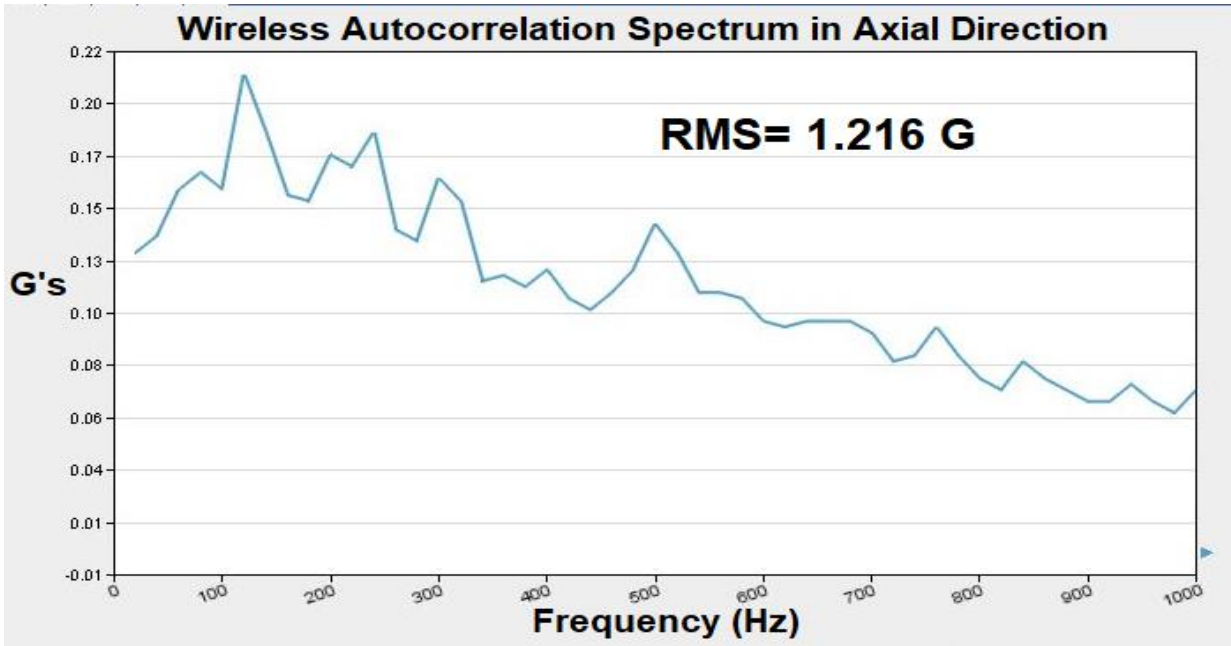

(b)

Figure 7. Wireless autocorrelation frequency spectrum acquired in axial direction (a) good bearing and (b) defective bearing 
The RMS vibration spectral data of healthy and defective bearings in horizontal, vertical and axial direction shows that defective bearing has almost double RMS value than healthy bearing. It shows the severity of bearing faults appears in radial as well as in axial direction. The frequency spectrums of defective bearing in Figures 5-7 shows the unnecessary frequency peaks which are required to be investigated for detailed analysis and root cause analysis (RCA). The comparison data in Table 2 shows that when a fault appears and progressively increases in severity, the peak g-level correspondingly trend upward in radial and axial direction of roller bearing frequency spectrum.

Table 2. Data of defective and good bearings based on 1000 F-MAX

\begin{tabular}{lcc}
\hline Accelerometer plane & Defective bearing (G's) & Good bearing (G's) \\
\hline Horizontal & 2.198 & 1.069 \\
Vertical & 2.774 & 1.728 \\
Axial & 1.216 & 0.528 \\
\hline
\end{tabular}

The acquired wireless vibration signals have been analyzed with AMS software on analysis unit. The data acquired in horizontal direction has been analyzed for capturing the resonance frequencies of bearing components. Figure 8 show the vibration data (frequency \& time wave) acquired on healthy and damaged bearing. The spectrum and waveform indicate clear difference in G's amplitude captured from stress wave generated in healthy and faulty bearing. The spectrums of faulty bearing show with clear fault of cage (FTF) and inner race fault (BPFI) frequency as calculated in Table 2. This is clear identification of faults at an early stage. It can be clearly observed in the faulty bearing spectrum that a high energy vibration zone is present around the $120 \mathrm{~Hz}$ and $480 \mathrm{~Hz}$ corresponds to natural frequency of ball spin frequency and inner race fault frequency.
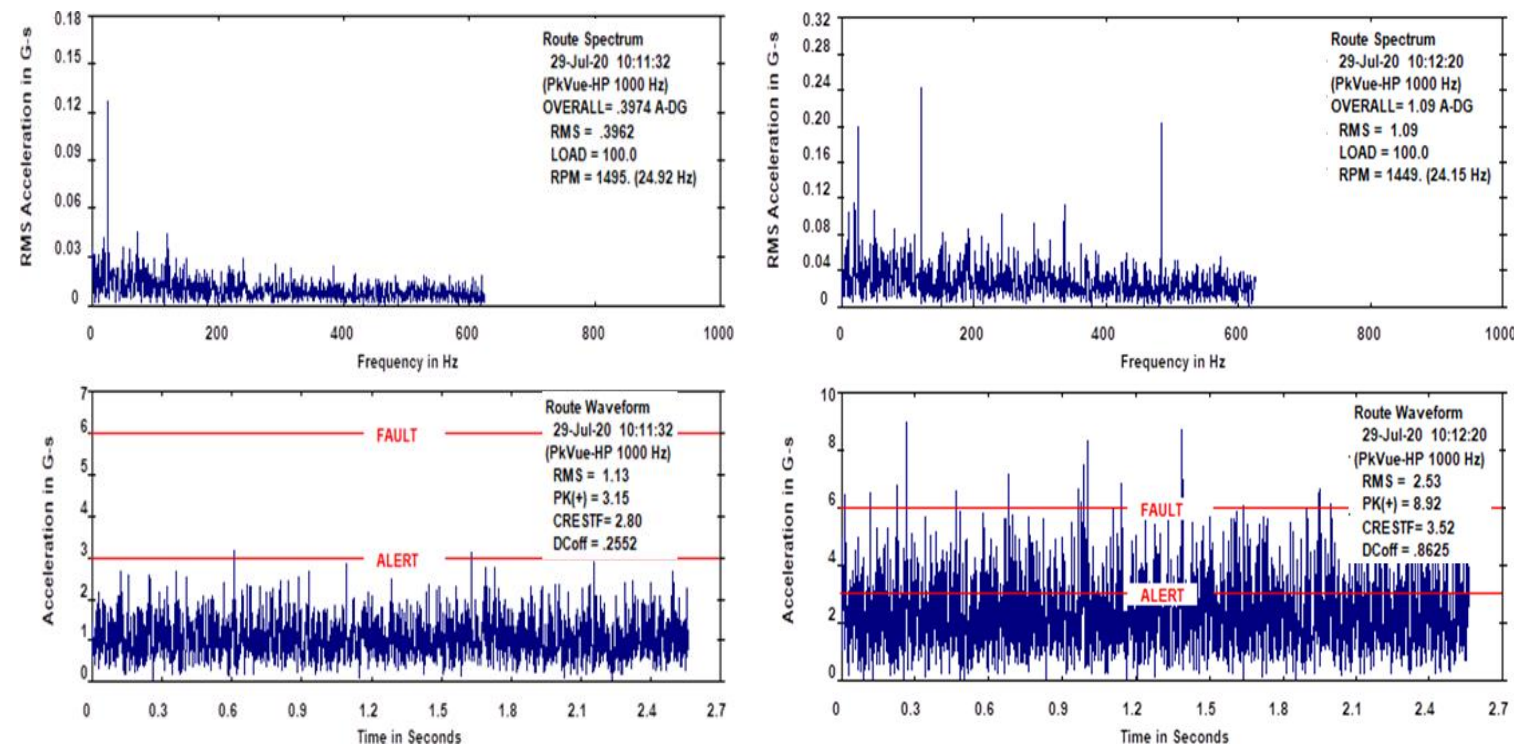

Figure 8. Wireless frequency and timewave spectrum recorded on faulty and good bearings

The time wave form has high Pk-Pk value in faulty bearing i.e $8.92 \mathrm{G}$ 's and crest factor of 3.52 is observed in faulty bearing. Whereas Pk-Pk value of good bearing in time waveform has significant decrease in signal amplitude which is $3.15 \mathrm{G}$ 's and crest factor is 2.80 . The spectrum alert (in time wave form) provides alarm thresholds. When a fault appears, it progressively increases and peak g-level will correspondingly trend upward. The zoom analysis of frequency spectrum of faulty bearing is shown in Figure 9 which display the marked peak frequencies captured at $9.31 \mathrm{~Hz}, 120 \mathrm{~Hz}$ and $480 \mathrm{~Hz}$. These frequencies match with BPFI and FTF and their hormonics as calculated in Table 1. The comparative scenario of frequency spectrum and timewave form recorded on good and faulty bearing provides the ability to carry out severity assessment of fault. 

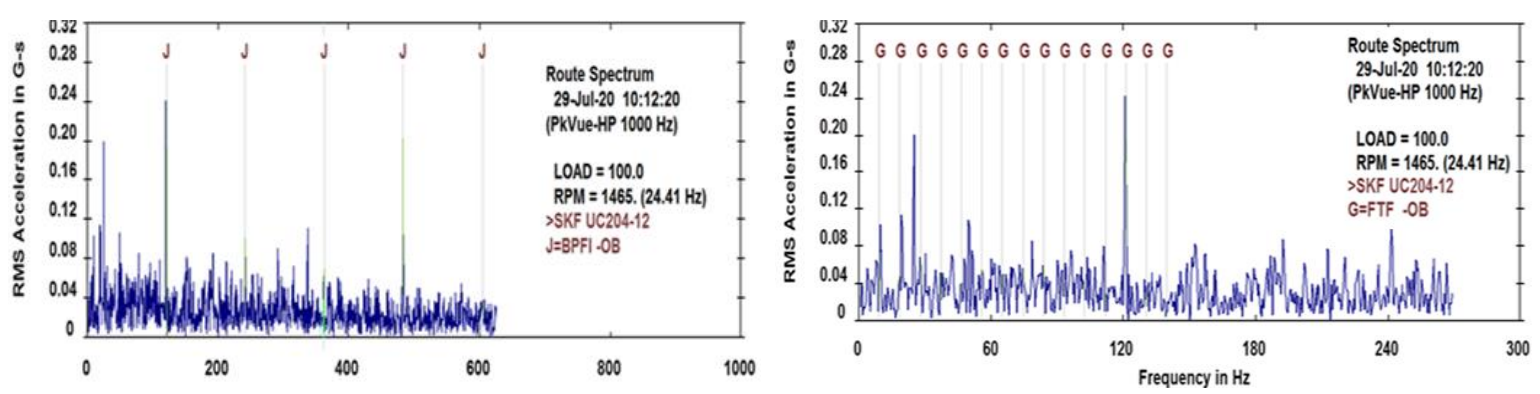

Figure 9. Defective bearing frequency spectrum showing inner race fault and cage fault

\section{CONCLUSION}

The WSN accompany with signal aautocorrelation technique has been implemented for early fault diagnostics of roller bearings. Based on the experimental results, it has been proved that autocorrelation technique with WSN is capable of acquiring data in high frequency region for early faults diagnosis and severity assessment of rolling element bearings with wireless signal transfer. From the analysis results obtained from healthy and defective bearing, we may conclude that in the faulty bearing, excitation in the high frequency zone is generated which may be detected at an early stage. The Stress waves generated due to fault events exhibit the the peak values associated with resonance frequency which are useful for early fault detection in roller bearings. The following recommendations are also may be considered: the sampling frequency and number of points must be sufficient to diagnose the harmonics of fault frequencies; F-Max must be three times higher than the BPFI fault frequency for rolling element bearings; the setting of high-pass filter should be greater than the maximum bandwidth value for capturing the peak frequencies in signal autocorrelation; the trending parameters are $\mathrm{Pk}-\mathrm{Pk}$ value in timewave form and energy in frequency spectrum.

\section{REFERENCES}

[1] Y. Bao, Z. Shi, X. Wang, and H. Li, "Compressive sensing of wireless sensors based on group sparse optimization for structural health monitoring," Structural Health Monitoring, vol 17, no. 4, pp. 1-14, 2018, doi: 10.1177/1475921717721457.

[2] R. S. Carbajo, A. Staino, K. P. Ryan, B. Basu, and C. Mc Goldrick, "Characterisation of Wireless Sensor Platforms for Vibration Monitoring of Wind Turbine Blades," ISSC 2011 : The 22nd IET Irish Signals and Systems Conference, 2011.

[3] P. Saxena and N. Tandon, "Fault Diagnostics and Health Monitoring of Machines Using Wireless Condition Monitoring Systems," International Journal of Scientific \& Engineering Research, vol. 6, no. 4, pp. 178-182, April-2015.

[4] M. V. Sergievskiy and S. N. Syroezhkin, "The Use of Wireless Sensor Technologies for Condition Monitoring of Modern Aircraft Structures,” Modern Applied Science, vol. 9, no. 8; pp. 262-269, 2015, doi: 10.5539/mas.v9n8p262.

[5] D. Vujić, R. Stojić, and Z. Filipović, "Wireless sensor networks technology in Aircraft structural health monitoring," 5th International Conference on Defensive Technology, pp. 141-147, 2012.

[6] W. Contreras and S. Ziavras, "Efficient structural health monitoring with wireless sensor networks using a vibration-based frequency domain pattern matching technique," 2017 IEEE 8th Annual Ubiquitous Computing, Electronics and Mobile Communication Conference (UEMCON), 2017, pp. 356-362, doi: 10.1109/UEMCON.2017.8249074.

[7] A. Khan and D. Zanwar, "Condition Monitoring of Oil using Wireless Sensor Network," International Journal of Engineering Trends and Technology (IJETT), vol. 35, no. 2, pp. 74-79, May 2016.

[8] A. L. Michala and I. Lazakis, "Ship machinery and equipment wireless condition monitoring system," Proceedings of the International Conference of Maritime Safety and Operations, pp.63-69, 2016.

[9] I. O. Olalere and M. Dewa, "Early fault detection of elevators using remote condition monitoring through iot technology," South African Journal of Industrial Engineering, vol. 29, no. 4, pp. 17-32, December 2018, doi: 10.7166/29-4-1947.

[10] M. E. Elnady, J. K. Sinha and S. O. Oyadiji, "Identification of Critical Speeds of Rotating Machines Using On-Shaft Wireless Vibration Measurement," Journal of Physics: Conference Series, vol. 364, 2012, doi: 10.1088/1742-6596/364/1/012142.

[11] A. S. R. Murthy, Y. K. V P. Ram, and K. S. Krishna, "Fault diagnosis of pump-motorset by using condition monitoring and IOT technique," International Journal of Mechanical Engineering and Technology (IJMET), vol. 9, no. 4, pp. 828-836, April 2018.

[12] Seenivasan V, Ponkumar K, Venkatraman R, and Jeslindrusilanesamalar J, "Induction motor condition monitoring and controlling based on IOT," International Research Journal of Engineering and Technology (IRJET), vol. 6, no. 3, pp. 7157-7162, Mar 2019.

[13] A. J. Rane and P. G. Khedkar, "Design and Implementation of Wireless Sensor Network for Machine Condition Monitoring and Fault Diagnosis," International Journal of Engineering Science and Computing, pp. 1079-1083, 2015, doi: 10.4010/2015.299.

[14] J. Medina-García, T. Sánchez-Rodríguez, J. A. G. Galán, A. Delgado, F. Gómez-Bravo, and R. Jiménez, “A Wireless Sensor System for Real-Time Monitoring and Fault Detection of Motor Arrays," Sensors, vol. 17, no. 3, 464, 2017, 10.3390/s17030469.

[15] S. Korkua, H. Jain, W. -J. Lee and C. Kwan, "Wireless health monitoring system for vibration detection of induction motors," 2010 IEEE Industrial and Commercial Power Systems Technical Conference-Conference Record, 2010, pp. 1-6, doi: 10.1109/ICPS.2010.5489899.

[16] A. A. Vinaya, S. Yulianto, Q. A. M. O. Arifianti, D. Arifianto, and A. S. Aisjah, "Machinery Signal Seperation using non-negative matrix factorization with real mixing," Bulletin of Electrical Engineering and Informatics, vol. 9, no. 4, pp. 1468-1476, 2020, doi: 10.11591/eei.v9i4.1956.

[17] X. Xu, M. Zhao, J. Lin, and Y. Lei, "Envelope harmonic-to-noise ratio for periodic impulses detection and its application to bearing diagnosis," Measurement, vol. 91, pp. 385-397, 2016, doi: 10.1016/j.measurement.2016.05.073. 
[18] Y. Ren, W. Li, Z. Zhu and F. Jiang, "ISVD-Based In-Band Noise Reduction Approach Combined With Envelope Order Analysis for Rolling Bearing Vibration Monitoring Under Varying Speed Conditions," in IEEE Access, vol. 7, pp. 32072-32084, 2019, doi: 10.1109/ACCESS.2019.2902851.

[19] T. Yassine, L. Sidahmed and O. Z. Mohamed, "Bearing Fault Classification Based on Envelope Analysis and Artificial Neural Network," 2019 International Conference on Advanced Electrical Engineering (ICAEE), 2019, pp. 1-5, doi: 10.1109/ICAEE47123.2019.9015123.

[20] G. Feng, H. Zhao, F. Gu, P. Needham, and A. D. Ball, "Efficient implementation of envelope analysis on resources limited wireless sensor nodes for accurate bearing fault diagnosis," Measurement, vol. 110, pp. 307-318, 2017, doi:10.1016/j.measurement.2017.07.009.

[21] W. Ikram et al., "Vibration-based wireless machine condition monitoring system," Proceedings of the 2014 IEEE Emerging Technology and Factory Automation (ETFA), 2014, pp. 1-4, doi: 10.1109/ETFA.2014.7005277.

[22] S. Sadiki, M. Ramadany, M. Faccio, D. Amegouz, and S. Boutahari, "Implementation of a remote monitoring system for conditionbased maintenance using Wireless sensor network: case study," Journal of Theoretical and Applied Information Technology, vol. 96, no. 15 , pp. 4770-4782, 2018.

[23] B. Myhrea, S. Petersena, and R. Ugarellib, "Using Wireless Vibration Monitoring to Enable Condition-Based Maintenance of Rotating Machinery in the Water and Wastewater Industries," Procedia Engineering, vol. 89, pp. 1397-1403, 2014, doi: 10.1016/j.proeng.2014.11.465.

[24] A. S. Ramirez, R. Loendersloot, and T. Tinga, "Vibration Based Blind Identification of Bearing Failures for Autonomous Wireless Sensor Nodes," Proceedings of the European Conference of the Prognostics and Health Management Society, pp. $452-462,2014$.

[25] G. Feng, X. Tian, J. X. Gu, D. Yang, F. G. and A. D. Balla, "An adaptive envelope analysis in a wireless sensor network for bearing fault diagnosis using fast kurtogram algorithm," 27th International Congress of Condition Monitoring and Diagnostic Engineering (COMADEM), Australia, 2014

[26] Guo-Jin Feng, J. Gu, D. Zhen, M. Aliwan, Feng-Shou Gu, and A. D. Ball, "Implementation of Envelope Analysis on a Wireless Condition Monitoring System for Bearing Fault Diagnosis," International Journal of Automation and Computing, vol. 12, pp. 14 24, 2015, doi: 10.1007/s11633-014-0862-x.

[27] S. Lu, P. Zhou, X. Wang, Y. Liu, F. Liu, and J. Zhao, "Condition monitoring and fault diagnosis of motor bearings using undersampled vibration signals from a wireless sensor network," Journal of Sound and Vibration, vol. 414, pp. 81-96, 2018, doi:10.1016/j.jsv.2017.11.007.

\section{BIOGRAPHIES OF AUTHORS}

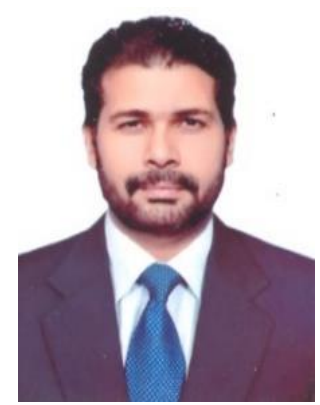

Ghulam Mustafa (iD 81 SC P received the bachelor's and master's degree in mechanical engineering from the University of Engineering and Technology, Taxila, Pakistan, and currently involved in research work of wireless condition monitoring of rotating equipment as Ph.D. Scholar in University of Engineering and Technology, Taxila, Pakistan. His research interests include vibration analysis and machine fault diagnostic of rotating and static equipment. He can be contacted at email: ghulam.mustafa@students.uettaxila.edu.pk.

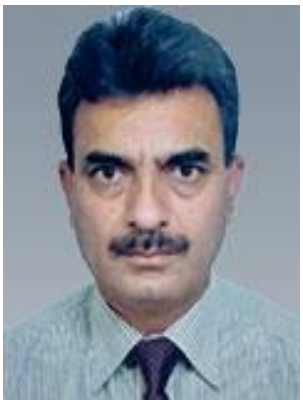

Shahab Khushnood (iD ) SC P received the bachelor's and master's degree in mechanical engineering from the University of Engineering and Technology, Lahore, Pakistan, and the Ph.D. degree from the National University of Science and Technology, Rawalpindi, Pakistan, in 2005. He served as the Dean for the Faculty of Mechanical and Aeronautical Engineering, University of Engineering and Technology, Taxila. Currently, he is serving in WAH Engineering College, WAH, Pakistan. His research interests include machine condition monitoring with vibration analysis, flow induced vibration of shell and tube heat exchanger, heat transfer analysis in heat exchangers. He can be contacted at email: shahab.khushnood@wecuw.edu.pk. 